\title{
Analysis Comparison of Algorithms for Determination Concentration of Chlorophyll-a in Traditional and Intensive Milkfish Ponds Using LANDSAT 8 Images
}

\author{
Nurhadi Bashit, Abdi Sukmono, Baskoro Agum Gumelar \\ Program Studi Teknik Geodesi, Fakultas Teknik, Universitas Diponegoro, INDONESIA
}

\section{Article History:}

Received 30 Pctober 2018

Received in revised form 10 December 2018

Accepted 14 December 2018

Available online 31 January 2019

\section{Keywords:}

Chlorophyll-a, Milkfish, Intensive ponds,

Traditional ponds

\section{Corresponding Author:}

Nurhadi Bashit

Email: nurhadi.bashit@live.undip.ac.id

\begin{abstract}
Indonesia is an Archipelago Country which has potential resources in the coastal areas, one of which is found on the northern coast of Java. The coastal area is an important area to be reviewed, one of which is the use of coastal resources by paying attention to the condition of the ecosystem that remains stable. Opportunities for coastal area utilization in the field of fisheries are in the form of fishing activities or fish farming, especially pond cultivation activities. Based on data from the Department of Marine and Fisheries of the Province of Central Java in 2010, pond cultivation is one of the potential resources on the coast. This potential is supported by the government to increase fish production in order to increase the consumption of fish in the community. Therefore, it is necessary to choose the most effective method of pond cultivation between traditional methods and intensive methods to optimize fish production. One indicator of effectiveness between the two methods can be seen from the phytoplankton distribution. Phytoplankton contains chlorophyll-a in the body and is a natural food from fish. Phytoplankton provides important ecological functions for the aquatic life cycle by serving as the basis of food webs in water. Phytoplankton also functions as the main food item in freshwater fish culture and seawater fish cultivation. Therefore, it is necessary to know the chlorophyll-a concentration in the ponds of traditional and intensive methods to determine the concentration chlorophyll-a of the two pond methods. One method used to determine the concentration of chlorophyll-a using remote sensing technology. Remote sensing technology can be used to determine the concentration of chlorophyll-a using the Wouthuyzen, Wibowo, Pentury, Much Jisin Arief and Lestari Laksmi algorithms. The results showed that the Pentury algorithm was relatively better to determine the concentration of chlorophyll-a in shallow waters (ponds). The lowest concentration of chlorophyll-a in traditional ponds is $0.47068 \mathrm{mg} / \mathrm{m} 3$, the highest concentration is $1.95017 \mathrm{mg} / \mathrm{m} 3$ and the average concentration is $1.12893 \mathrm{mg} / \mathrm{m} 3$, while in intensive ponds the lowest concentration is $0.36713 \mathrm{mg} / \mathrm{m3}$, the concentration the highest is 3.17063 $\mathrm{mg} / \mathrm{m} 3$ and the average concentration is $1.53556 \mathrm{mg} / \mathrm{m3}$.
\end{abstract}

(C) Author(s) 2018. This is an open access article under the Creative Commons Attribution-ShareAlike 4.0 International License (CC BY-SA 4.0).

\section{Introduction}

Indonesia merupakan Negara Kepulauan karena Negara Indonesia terdiri dari banyak sekali pulau yang membentang dari Sabang di ujung barat hingga ke pulau Merauke di ujung timur. Negara kepulauan juga berasal dari sebutan lama Negara Indonesia yang bernama
Nusantara. Nusantara berarti juga banyak pulau atau kepulauan. Indonesia merupakan Negara kepulauan yang berarti memiliki potensi sumberdaya pada wilayah pesisir pantai, salah satunya terdapat pada wilayah pesisir pantai utara Jawa. Wilayah pesisir merupakan wilayah yang penting untuk ditinjau salah satunya yaitu pemanfaatan 
sumberdaya wilayah pesisir dengan memperhatikan kondisi ekosistem yang tetap stabil. Peluang pemanfaatan wilayah pesisir dalam bidang perikanan yaitu berupa kegiatan penangkapan ataupun usaha budidaya ikan khususnya kegiatan budidaya tambak.

Budidaya tambak merupakan salah satu sumber daya yang potensial berada di pesisir pantai. Potensi tersebut didukung oleh pemerintah untuk meningkatkan produksi ikan guna meningkatkan konsumsi ikan masyarakat. Oleh karena itu, perlu pemilihan metode budidaya tambak yang paling efektif antara metode tradisional dan metode intensif untuk mengoptimalkan produksi ikan, salah satunya budidaya berupa ikan bandeng. Salah satu indikator efektifitas antara kedua metode tersebut dapat dilihat dari kandungan fitoplankton. Analisis isi saluran pencernaan makanan menunjukkan bahwa makanan utaman ikan bandeng adalah plankton, yang terdiri dari fitoplankton (35,2-56,42\%). Kelimpahan plankton yang tinggi berperan penting dalam produktivitas suatu perairan dan merupakan sumber pakan alami yang dapat dimanfaatkan ikan, khususnya ikan pemakan fitoplankton (Triyanto, 2014). Fitoplankton mengandung klorofil-a di dalam tubuhnya dan merupakan pakan alami dari ikan.

Fitoplankton mampu melakukan fotosintesis karena mengandung klorofil-a sehingga distribusi klorofil-a dapat dijadikan ukuran bagi biomassa fitoplankton dalam suatu perairan. Klorofil-a adalah pigmen yang umumnya ada pada fitoplankton dan fitoplankton merupakan faktor utama untuk menghasilkan produksi primer dalam rantai makanan di perairan (Juniarta, 2016). Purnamaningtyas (2009) melaporkan bahwa makanan utama ikan bandeng yang diamati pada September 2008-Januari 2009 terdiri dari fitoplankton $(50,16-77,76 \%)$ dan zooplankton (20,02-48,72 \%), serta detritus dan tumbuhan dalam jumlah yang sedikit (Purnamaningtyas 2009 dalam Triyanto 2014). Fitoplankton memberikan fungsi ekologis penting untuk semua kehidupan air dengan melayani sebagai dasar dari jaring makanan di air. Fitoplankton juga berfungsi sebagai item makanan utama di budidaya perikanan dan budidaya laut. Oleh karena itu, perlunya mengetahui kosentrasi klorofil-a pada tambak metode tradisional dan metode intensif agar mengetahui kosentrasi kedua metode tambak tersebut.

Pengujian konsentrasi klorofil-a bisa dilaksanakan dengan metode konvensional (uji laboratorium), namun metode ini membutuhkan biaya yang relatif lebih mahal dan waktu yang relatif lebih lama. Oleh karena itu, peneliti memanfaatkan teknologi pengindraan jauh untuk mengetahui konsentrasi klorofil-a. Teknologi pengindraan jauh merupakan teknologi menggunakan data hasil perekaman satelit berupa sebuah citra satelit yang dapat dioleh sesuai dengan keperluan. Citra satelit merupakan suatu gambaran permukaan bumi yang direkam dengan suatu sensor melalui wahana satelit. Pemanfaatan citra satelit ini peneliti bermaksud untuk melakukan penelitian dengan mengenai algoritma terbaik untuk menentukan konsentrasi klorofil-a pada tambak bandeng tradisional dan tambak bandeng intensif menggunakan citra landsat 8 .

Algoritma yang digunakan pada penelitian ini untuk menentukan konsentrasi klorofil-a adalah algoritma
Wouthuyzen, Wibowo, Pentury, Much Jisin Arief dan Lestari Laksmi. Pemilihan metode-metode pada penelitian ini disebabkan karena metode yang dipilih dapat diterapkan diperairan dangkal. Penelitian ini diharapkan bisa memberikan masukan kepada para petani tambak mengenai metode budidaya yang lebih efisien dan diharapkan bisa membantu tercapainya visi dari Dinas Kelautan dan Perikanan Provinsi Jawa Tengah melalui pertimbangan metode budidaya yang lebih efisien. Penelitian ini memberikan informasi kepada petani tambak mengenai perbedaan konsentrasi klorofil-a antara tambak tradsional dan tambak intensif sehingga bahan pertimbangan petani tambak dalam menentukan metode yang digunakan untuk meningkatkan hasil budidaya ikan.

\section{Data dan Metodologi}

Bagian ini menjelaskan secara rinci tentang penelitian yang dilakukan, meliputi lokasi penelitian, data yang digunakan, dan metodologi yang diterapkan.

\subsection{Data dan Lokasi}

1. Penelitian ini menggunakan data primer dan sekunder dalam pelaksanaannya antara lain:

1. Sampel air di tambak tradisional Kecamatan Sayung, Kabupaten Demak diambil pada tanggal 25 Oktober 2017 dan sampel air di tambak intensif Kecamatan Juwana, Kabupaten Pati diambil pada tanggal 3 November 2017.

2. Citra Landsat 8 Path 120 Row 65 level 1T diakuisisi tanggal 25 Oktober 2017 dan citra Landsat 8 Path 119 Row 65 Level 1T diakuisisi tanggal 3 November 2017.

3. Informasi pendukung mengenai jenis tambak dari para petani tambak ikan bandeng dengan cara wawancara langsung.

2. Lokasi penelitian ini terdapat di Provinsi Jawa Tengah terdapat 2 lokasi dengan 2 metode budidaya yang berbeda antara lain tambak tradisional di Kecamatan Sayung, Kabupaten Demak dan tambak intensif di Kecamatan Juwana, Kabupaten Pati, Provinsi Jawa Tengah.

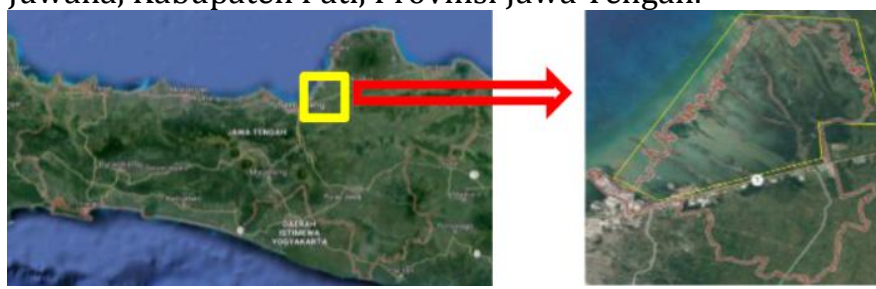

Gambar 2.1 Lokasi Penelitian Tambak Tradisional

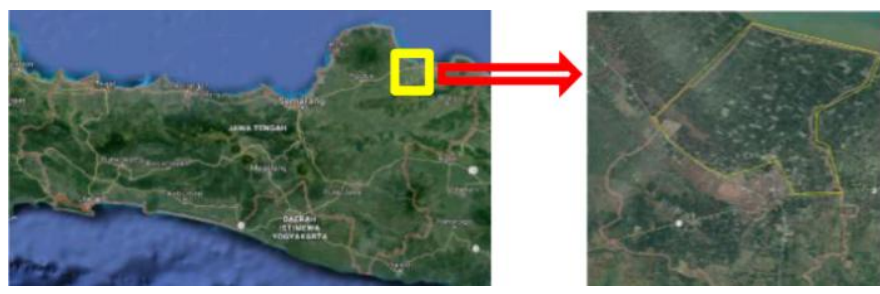

Gambar 2.2 Lokasi Penelitian Tambak Intensif

2.2. Metodologi 
1. Pengambilan Sampel

Data klorofil-a in situ diambil secara langsung di tambak tradisional Kecamatan Sayung, Kabupaten Demak pada tanggal 25 Oktober 2017 dan di tambak intensif Kecamatan Juwana, Kabupaten Pati pada tanggal 3 November 2017. Pengambilan data in situ dilakukan pada tanggal tersebut dikarenakan akuisisi satelit Landsat 8 berlangsung pada tanggal tersebut. Penentuan waktu merupakan perkiraan dari resolusi temporal satelit landsat 8 selama 16 hari merekam daerah yang sama. Proses pengambilan data in situ diusahakan mendekati waktu akuisisi data satelit yaitu antara pukul 09:00 WIB sampai pukul 11:00 WIB.

Teknik pengambilan sampel klorofil-a pada penelitian ini sebagai berikut:

1. Pengambilan sampel dilakukan pada hari yang sama dengan akuisisi citra Landsat 8 dan dilakukan pada cuaca yang cerah (tidak berawan). Tujuannya supaya citra yang akan diolah bebas dari tutupan awan.

2. Pengambilan sampel dilakukan pada kedalaman air yang masih dapat ditembus oleh cahaya matahari, hal ini dikarenakan fitoplankton membutuhkan sinar matahari untuk melakukan fotosintesis.

3. Koordinat masing - masing sampel dicatat.

4. Pengambilan masing-masing sampel menggunakan botol dengan volume 1,5 liter yang sebelumnya sudah diberi label supaya tidak tertukar pada saat pengujian di laboratorium.

5. Sampel air yang sudah diambil segera dimasukkan kedalam cooling box supaya fitoplankton tidak rusak Fitoplankton yang rusak mengakibatkan fitoplankton tidak bereaksi dengan aseton bila diuji di laboratorium.

Pelaksanaan uji laboratorium lebih baik dilakukan pada hari yang sama dengan pengambilan sampel untuk mencegah rusaknya fitoplankton. Apabila pelaksanaan uji laboratorium tidak bisa dilakukan pada hari yang sama dengan hari pengambilan sampel, maka sampel harus disaring menggunakan kertas saring dan kertas hasil penyaringan dimasukkan kedalam freezer sampai waktu uji laboratorium dilaksanakan.

\section{Kalibrasi Radiometrik}

Koreksi radiometrik dilakukan untuk memperbaiki kesalahan atau distorsi yang diakibatkan oleh tidak sempurnanya operasi dan sensor, atenuasi gelombang elektromagnetik oleh atmosfer, variasi sudut pengambilan data, variasi sudut eliminasi, sudut pantul dan lain-lain yang dapat terjadi pengambilan, pengiriman dan perekaman data. Tujuan utama dari kalibrasi radiometrik adalah mengubah nilai digital number menjadi nilai radian, reflektan maupun nilai brightness temperature untuk kanal infra merah termal (USGS, 2016).

Kalibrasi radiometrik bisa dilakukan secara manual menggunakan parameter-parameter yang disimpan dalam metadata dari Landsat 8 maupun secara otomatis menggunakan software. Transformasi nilai DN menjadi reflektan ToA dapat dilihat pada persamaan 1 .

$$
\rho \lambda^{\prime}=M \rho Q c a l+A \rho
$$

Keterangan:

$\rho \lambda^{\prime} \quad=$ Reflektan ToA, tanpa koreksi sudut matahari

$M \rho=$ Reflectance_Mult_Band_x, di mana $\mathrm{x}$ adalah nomer band

$A \rho \quad=$ Reflectance_Add_Band_x, di mana $\mathrm{x}$ adalah nomer band

Qcal = Nilai Digital Number $(\mathrm{DN})$

\section{Pemotongan Citra}

Pemotongan citra dapat digunakan untuk data spasial maupun data spektral. Pemotongan citra dapat dilakukan berdasarkan titik koordinat, jumlah pixel atau hasil zooming daerah tertentu (Arhatin, 2010). Pemotongan atau cropping citra dilakukan untuk mendapatkan daerah penelitian dengan maksud untuk dapat melakukan pengolahan data yang lebih terfokus, terinci dan teroptimal. Pemotongan citra memiliki nilai utilitas lainnya, yaitu memperkecil daerah yang akan dikaji sesuai dengan area of interest. Pemotongan citra dapat dilakukan sesuai dengan bentuk poligon yang diinginkan seperti pembatasan wilayah kabupaten, kecamatan atau desa.

\section{Deliniasi Batas Daratan dan Perairan}

Menurut Putri (2014), deliniasi adalah penarikan garis batas sementara suatu wilayah atau suatu negara di atas peta. Proses deliniasi juga dilakukan secara digitasi on screen. Digitasi on screen merupakan suatu teknik digitasi atau proses konversi dari data format raster ke dalam format vektor. Peta yang akan digitasi terlebih dahulu harus dibawa ke dalam format raster baik melalui proses scanning dengan alat scanner atau dengan pemotretan. Jika data tersebut merupakan citra hasil foto udara ataupun satelit maka langsung dilakukan digitasi.

\section{Algoritma Wouthuyzen}

Sidabutar (2009) menjelaskan bahwa Wouthuyzen (1991) mengembangkan algoritma dengan memanfaatkan citra Landsat-TM di perairan Teluk Omura Jepang. Hasil penelitiannya menunjukkan bahwa rasio antara kanal 1 dengan kanal 2 atau kanal 2 dengan kanal 1 mempunyai hubungan yang sangat kuat terhadap konsentrasi klorofila untuk semua musim. Rasio kanal 2 dengan kanal 1 adalah yang paling konsisten untuk semua musim. Empat algoritma yang berbeda selama empat musim dalam setahun untuk musim gugur, dingin, semi dan panas.

$$
\begin{aligned}
& C h l-a=28,895(B 2 / B 3)-9,596 \\
& C h l-a=30,344(B 2 / B 1)-7,684 \\
& C h l-a=21,279(B 2 / B 1)-0,908 \\
& C h l-a=10,359(B 2 / B 1)-2,355
\end{aligned}
$$

Keterangan:

Chl-a: Klorofil-a

B1 : Kanal 1 Landsat 7 ETM+ (Band Biru)

B2 : Kanal 2 Landsat 7 ETM+ (Band Hijau)

B3 : Kanal 3 Landsat 7 ETM+ (Band Merah)

\section{Algoritma Wibowo}

Wibowo dalam Sidabutar (2009), melakukan penelitian klorofil-a di perairan pesisir Cirebon, Lampung, Jambi dan 
Jepara dengan mengembangkan algoritma untuk pendugaan klorofil-a menggunakan citra Landsat-TM. Algoritma Wibowo dapat dilihat pada persamaan 2.

$$
C h l-a=2,41(B 3 / B 2)+0,187
$$

Keterangan:

$$
\begin{array}{ll}
\text { Chl-a } & \text { : Klorofil-a } \\
\text { B2 } & \text { : Kanal } 2
\end{array}
$$

Landsat $7 \mathrm{ETM}+($ Band Hijau)

B3 : Kanal 3 Landsat 7 ETM+ (Band Merah)

\section{Algoritma Pentury}

Pentury dalam Sidabutar (2009), melakukan penelitian klorofil-a di perairan Teluk Ambon dengan mengembangkan algoritma untuk pendugaan klorofil-a menggunakan citra Landsat-TM. Algoritma Pentury dapat dilihat pada persamaan 3 .

$$
C h l-a=2,3868(B 2 / B 1)+0,4671
$$

Keterangan:

Chl-a : Klorofil-a

B2 : Kanal 1 Landsat 7 ETM+ (Band Biru)

B3 : Kanal 2 Landsat 7 ETM+ (Band Hijau)

8. Algoritma Much Jisin Arief dan Lestari Laksmi

Much Jisin Arief dan Lestari Laksmi pada tahun 2006 melakukan penelitian untuk menganalisis kesesuaian perairan tambak di Kabupaten Demak dengan menggunakan parameter nilai klorofil-a, suhu permukaan perairan dan muatan padatan tersuspensi (TSS). Algoritma tersebut menghasilkan nilai klorofil-a 0,3682,852 pg/l. Algoritma yang digunakan oleh Much Jisin Arief dan Lestari Laksmi dapat dilihat pada persamaan 4.

$$
C h l-a=17,912\left(\frac{B 1-B 2}{B 1+B 2}\right)-0,3343
$$

Keterangan:

$$
\begin{array}{ll}
\text { Chl-a } & \text { : Klorofil-a } \\
B 1 & \text { : Kanal 1 Landsat } 7 \text { ETM+ (Band Biru) } \\
\text { B2 } & \text { : Kanal 2 Landsat 7 ETM+ (Band Hijau) }
\end{array}
$$

\section{Hasil dan Pembahasan}

\subsection{Hasil Pengujian Klorofil-a di Laboratorium}

Nilai absorbansi dan nilai konsentrasi klorofil-a masingmasing sampel pada tambak tradisional dapat dilihat pada Tabel 3.1.

Tabel 3.1 Hasil Uji Lab Sampel Tambak Tradisional

\begin{tabular}{cccccc}
\hline & \multicolumn{4}{c}{ Absorbansi } & Klorofil-a \\
\cline { 2 - 5 } Titik & $\begin{array}{c}\mathbf{6 3 0} \\
\mathbf{( n m )}\end{array}$ & $\begin{array}{c}\mathbf{6 4 7} \\
\mathbf{( n m})\end{array}$ & $\begin{array}{c}\mathbf{6 6 4} \\
\mathbf{( n m )}\end{array}$ & $\begin{array}{c}\mathbf{7 5 0} \\
\mathbf{( n m )}\end{array}$ & $\begin{array}{c}\text { mg/m } \\
\text { (nm }\end{array}$ \\
\hline D1 & 0,012 & 0,018 & 0,058 & 0,002 & 0,850880 \\
D2 & 0,017 & 0,021 & 0,065 & 0,002 & 0,954787 \\
D3 & 0,020 & 0,027 & 0,083 & 0,003 & 1,212907 \\
D4 & 0,010 & 0,014 & 0,043 & 0,002 & 0,608667 \\
D5 & 0,067 & 0,098 & 0,294 & 0,003 & 4,409547 \\
D6 & 0,039 & 0,044 & 0,132 & 0,003 & 1,950173 \\
D7 & 0,120 & 0,204 & 0,436 & 0,005 & 6,388920 \\
D8 & 0,042 & 0,061 & 0,170 & 0,005 & 2,488067 \\
D9 & 0,008 & 0,011 & 0,033 & 0,002 & 0,470680 \\
D10 & 0,029 & 0,045 & 0,126 & 0,003 & 1,854387 \\
\hline
\end{tabular}

Nilai konsentrasi klorofil-a hasil uji laboratorium didapatkan dari nilai absorbansi sampel pada panjang

\begin{tabular}{|c|c|c|c|c|c|}
\hline \multirow[b]{2}{*}{ Titik } & \multicolumn{4}{|c|}{ Absorbansi } & \multirow[b]{2}{*}{$\begin{array}{c}\text { Klorofil-a } \\
\mathrm{mg} / \mathrm{m}^{3}\end{array}$} \\
\hline & $\begin{array}{c}630 \\
(\mathrm{~nm})\end{array}$ & $\begin{array}{c}647 \\
(\mathrm{~nm})\end{array}$ & $\begin{array}{c}664 \\
(\mathrm{~nm})\end{array}$ & $\begin{array}{c}750 \\
(\mathrm{~nm})\end{array}$ & \\
\hline P1 & 0,046 & 0,062 & 0,202 & $-0,008$ & 4,748507 \\
\hline P2 & 0,009 & 0,013 & 0,041 & 0,004 & 0,565587 \\
\hline P3 & 0,001 & 0,003 & 0,017 & $-0,009$ & 0,385093 \\
\hline P4 & 0,007 & 0,015 & 0,048 & $-0,010$ & 0,849613 \\
\hline P5 & 0,001 & 0,003 & 0,015 & $-0,010$ & 0,367133 \\
\hline P6 & 0,019 & 0,023 & 0,070 & $-0,005$ & 1,124947 \\
\hline P7 & 0,045 & 0,067 & 0,214 & 0,005 & 3,170627 \\
\hline P8 & 0,049 & 0,060 & 0,171 & $-0,009$ & 2,696133 \\
\hline P9 & 0,033 & 0,050 & 0,161 & $-0,003$ & 2,478533 \\
\hline $\mathrm{P} 10$ & 0,029 & 0,043 & 0,137 & $-0,008$ & 2,182333 \\
\hline
\end{tabular}
gelombang $630 \mathrm{~nm}, 647 \mathrm{~nm}, 664 \mathrm{~nm}$, dan $750 \mathrm{~nm}$. Berdasarkan hasil uji sampel tambak tradisional di Kecamatan Sayung, konsentrasi klorofil-a terendah terdapat di titik D9 dengan nilai sebesar 0,47068 mg/m3, sedangkan konsentrasi klorofil-a tertinggi terdapat di titik D7 dengan nilai sebesar 6,38892 mg/m3.

Tabel 3.2 Hasil Uji Lab Sampel Tambak Intensif

Berdasarkan hasil uji sampel tambak intensif di Kecamatan Juwana, konsentrasi klorofil-a terendah terdapat di titik P5 dengan nilai sebesar 0,367133 mg/m3, sedangkan konsentrasi klorofil-a tertinggi terdapat di titik P1 dengan nilai sebesar 4,748507 mg/m3.

\subsection{Hasil Kalibrasi Radiometrik}

Koreksi radiometrik meliputi kalibrasi radiometrik dan koreksi atmosfer. Hasil kalibrasi radiometrik adalah reflektan ToA, sedangkan hasil koreksi atmosfer adalah reflektan BoA. Kenampakan citra setelah dilakukan koreksi radiometrik secara visual menjadi lebih terang, sedangkan nilai spektral berubah menjadi kisaran 0 sampai 1 .

\subsection{Hasil Algoritma Wouthuyzen}

Algoritma Wouthuyzen mempunyai empat rumus sesuai dengan masing - masing musim yang ada di Jepang. Rumus yang digunakan untuk penelitian ini adalah rumus Wouthuyzen pada musim panas. Band yang digunakan dalam algoritma Wouthuyzen adalah band 2 dan band 3 pada landsat 8 .

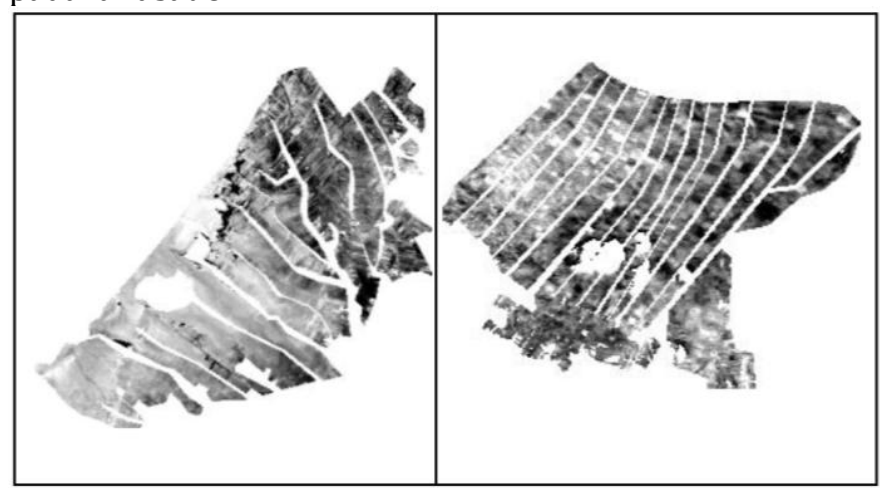

(a) Kecamatan Sayung

(b) Kecamatan Juwana

Gambar 3.1 Citra Hasil Algoritma Wouthuyzen 


\subsection{Hasil Algoritma Wibowo}

Hasil pengolahan konsentrasi klorofil-a algoritma Wibowo dkk menggunakan band 3 dan band 4 pada landsat 8 dapat dilihat pada Gambar 3.2.

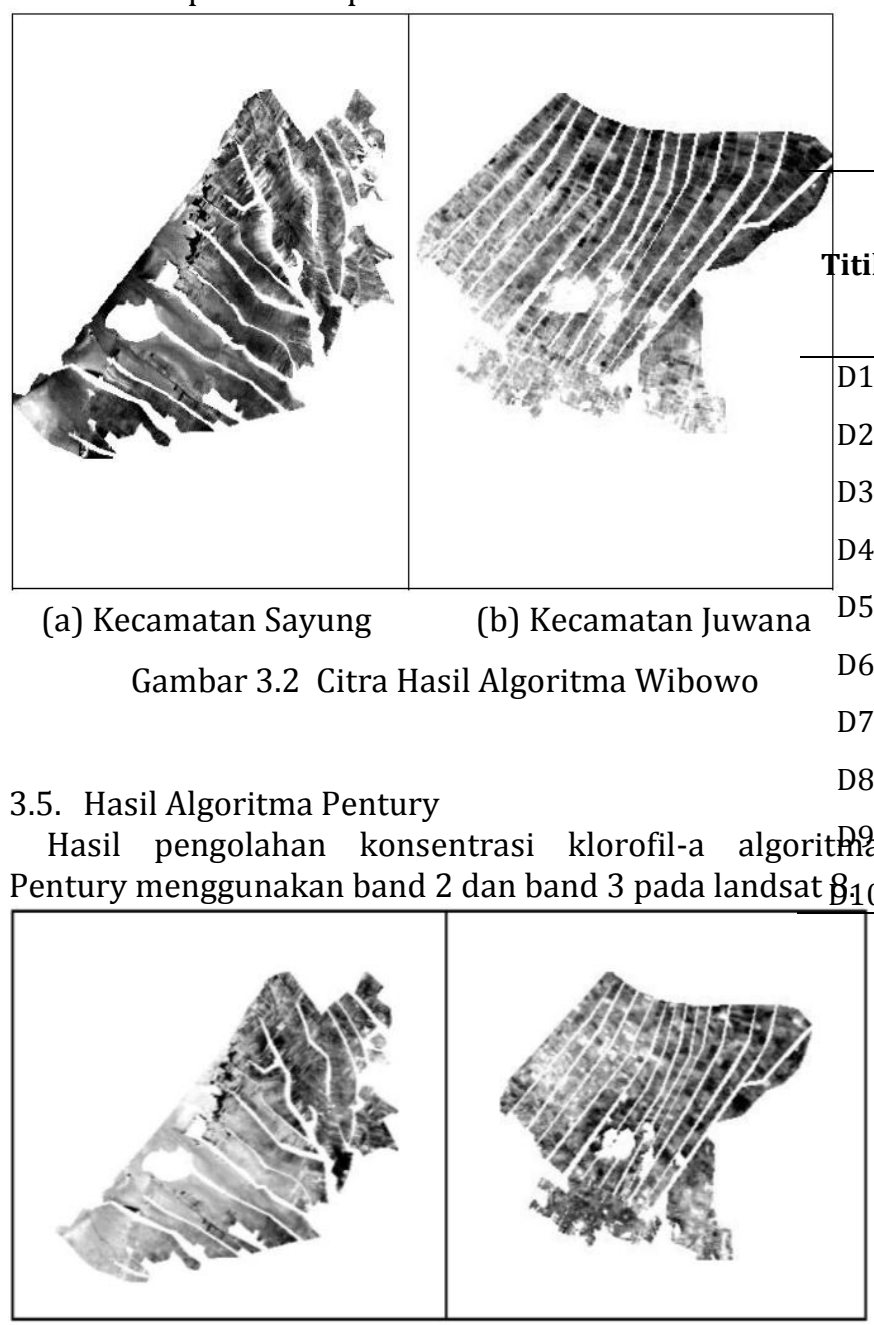

(a) Kecamatan Sayung

(b) Kecamatan Juwana

Gambar 3.3 Citra Hasil Algoritma Pentury

3.6. Hasil Algoritma Much Jisin Arief dan Lestari Laksmi Hasil pengolahan konsentrasi klorofil-a algoritma Much Jisin Arief dan Lestari Laksmi menggunakan band 2 dan band 3 pada landsat 8 .

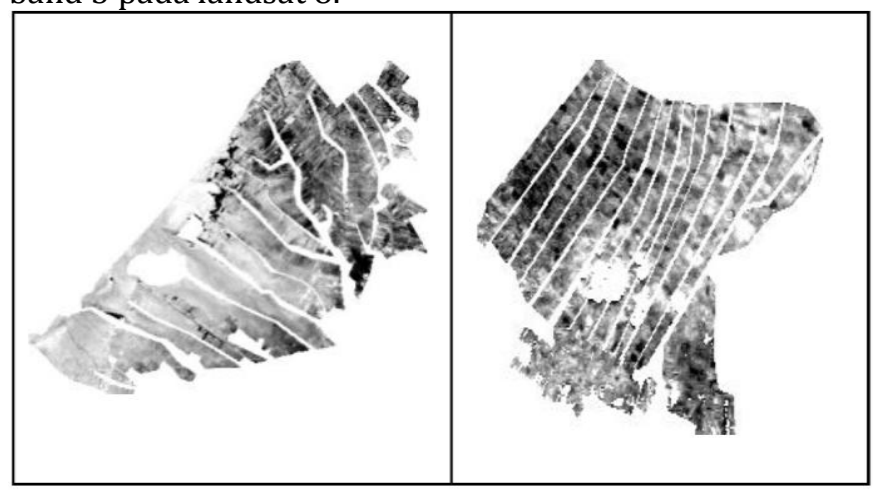

(a) Kecamatan Sayung

(b) Kecamatan Juwana

Gambar 3.4 Citra Hasil Algoritma Much Jisin Arief dan Lestari Laksmi
3.7. Perbandingan Konsentrasi Klorofil-a antara data Pengindraan Jauh dengan Uji Laboratorium

Hasil perhitungan konsentrasi klorofil-a masing-masing algoritma dan uji laboratorium pada tambak tradisional dapat dilihat pada Tabel 3.3.

Tabel 3.3 Konsentrasi Klorofil-a Tambak Tradisional Hasil Metode Pengindraan Jauh dan Uji Lab Hasil Pengolahan Data Pengindraan Jauh

\begin{tabular}{|c|c|c|c|c|}
\hline $\begin{array}{c}\text { Wouthuyzen } \\
\left(\mathrm{mg} / \mathrm{m}^{3}\right)\end{array}$ & $\begin{array}{l}\text { Wibowo } \\
\left(\mathrm{mg} / \mathrm{m}^{3}\right)\end{array}$ & $\begin{array}{l}\text { Pentury } \\
\left(\mathrm{mg} / \mathrm{m}^{3}\right)\end{array}$ & $\begin{array}{c}\text { Much } \\
\text { Jisin \& } \\
\text { Lestari } \\
\left(\mathrm{mg} / \mathrm{m}^{3}\right)\end{array}$ & $\begin{array}{l}\text { Uji Lab } \\
\mathrm{mg} / \mathrm{m}^{3}\end{array}$ \\
\hline 4,499522 & 2,375899 & 1,112239 & $-3,980981$ & 0,85088 \\
\hline 2,462297 & 1,98186 & 0,642845 & $-6,874959$ & 0,95478 \\
\hline 7,031894 & 2,95744 & 1,695719 & $-1,216122$ & 1,21290 \\
\hline 4,419361 & 2,162352 & 1,093769 & $-4,081846$ & 0,60866 \\
\hline 3,793925 & 2,545449 & 0,949664 & $-4,902461$ & 4,40954 \\
\hline 5,149739 & 2,605587 & 1,262054 & $-3,196273$ & 1,95017 \\
\hline 4,823318 & 2,964455 & 1,186844 & $-3,582937$ & 6,38892 \\
\hline 3,497995 & 2,440313 & 0,881479 & $-5,312809$ & 2,48806 \\
\hline 4,446938 & 3,048187 & 1,100123 & $-4,04704$ & 0,47068 \\
\hline 4,263574 & 2.786764 & 1.057875 & $-4,280595$ & 1.85438 \\
\hline
\end{tabular}

Hasil konsentrasi klorofil-a uji laboratorium di tambak tradisional menghasilkan nilai $0,47068 \mathrm{mg} / \mathrm{m} 3$ hingga 6,38892 mg/m3, sedangkan hasil konsentrasi klorofil-a metode pengindraan jauh untuk masing-masing algoritma menghasilkan nilai yang berbeda-beda. Algoritma Wouthuyzen menghasilkan nilai 2,462297 mg/m3 hingga $7,031894 \mathrm{mg} / \mathrm{m} 3$, algoritma Wibowo menghasilkan nilai $1,98186 \mathrm{mg} / \mathrm{m} 3$ hingga $3,048187 \mathrm{mg} / \mathrm{m} 3$, algoritma Pentury menghasilkan nilai $0,642845 \mathrm{mg} / \mathrm{m} 3$ hingga $1,695719 \mathrm{mg} / \mathrm{m} 3$, algoritma Much Jisin Arief dan Lestari Laksmi menghasilkan nilai $-6,874959 \mathrm{mg} / \mathrm{m} 3$ hingga $1,216122 \mathrm{mg} / \mathrm{m} 3$.

Hasil uji normalitas data antara nilai konsentrasi klorofil-a hasil algoritma pengindraan jauh dengan nilai konsentrasi klorofil-a hasil uji laboratorium pada tambak tradisional dapat dilihat pada Tabel 3.4 dan 3.5. Metode uji normalitas yang dipakai dalam penelitian ini adalah metode uji normalitas Kolmogorov Smirnov dengan menggunakan derajat kepercayaan 95\%.

Tabel 3.4 Uji Normalitas pada Tambak Tradisional

\begin{tabular}{ccccc}
\hline Parameter & $\begin{array}{c}\text { Algoritma } \\
\text { Wouthuy- } \\
\text { zen }\end{array}$ & $\begin{array}{c}\text { Algoritma } \\
\text { Wibowo }\end{array}$ & $\begin{array}{c}\text { Algoritma } \\
\text { Pentury }\end{array}$ & $\begin{array}{c}\text { Algoritma } \\
\text { Much Jisin } \\
\text { Arief Dan } \\
\text { Lestari } \\
\text { Laksmi }\end{array}$ \\
\hline $\begin{array}{c}\text { Jumlah Data } \\
\text { Standar } \\
\text { Deviasi }\end{array}$ & 7 & 7 & 7 & 7 \\
Absolut & 0,347 & 0,464 & 0,347 & 0,338 \\
Signifikansi & 0,224 & 0,273 & 0,224 & 0,209 \\
\hline
\end{tabular}


Algoritma Wouthuyzen, Pentury, Much Jisin Arief dan Lestari Laksmi memiliki nilai signifikansi 0,2 sedangkan algoritma Wibowo memiliki nilai signifikansi 0,125. Semua nilai signifikansi tersebut lebih besar dari 0,05 jadi dapat disimpulkan bahwa semua data tersebut terdistribusi secara normal.

Tabel 3.5 Uji Normalitas pada Tambak Intensif

\begin{tabular}{ccccc}
\hline Parameter & $\begin{array}{c}\text { Algoritma } \\
\text { Wouthuyzen }\end{array}$ & $\begin{array}{c}\text { Algoritma } \\
\text { Wibowo }\end{array}$ & $\begin{array}{c}\text { Algoritma } \\
\text { Pentury }\end{array}$ & $\begin{array}{c}\text { Algoritma } \\
\text { Much Jisin } \\
\text { Arief Dan } \\
\text { Lestari } \\
\text { Laksmi }\end{array}$ \\
\hline $\begin{array}{c}\text { Jumlah } \\
\text { Data } \\
\text { Standar } \\
\text { Deviasi }\end{array}$ & 9 & 9 & 9 & 9 \\
Absolut & 0,689 & 1,094 & 0,689 & 0,696 \\
Signifikansi & 0,165 & 0,211 & 0,165 & 0,166 \\
\hline
\end{tabular}

Algoritma Wouthuyzen, Wibowo, Pentury, Much Jisin Arief dan Lestari Laksmi semuanya memiliki nilai signifikansi 0,2 pada tambak intensif. Nilai signifikansi tersebut lebih besar dari 0,05 jadi dapat disimpulkan bahwa semua data tersebut terdistribusi secara normal.
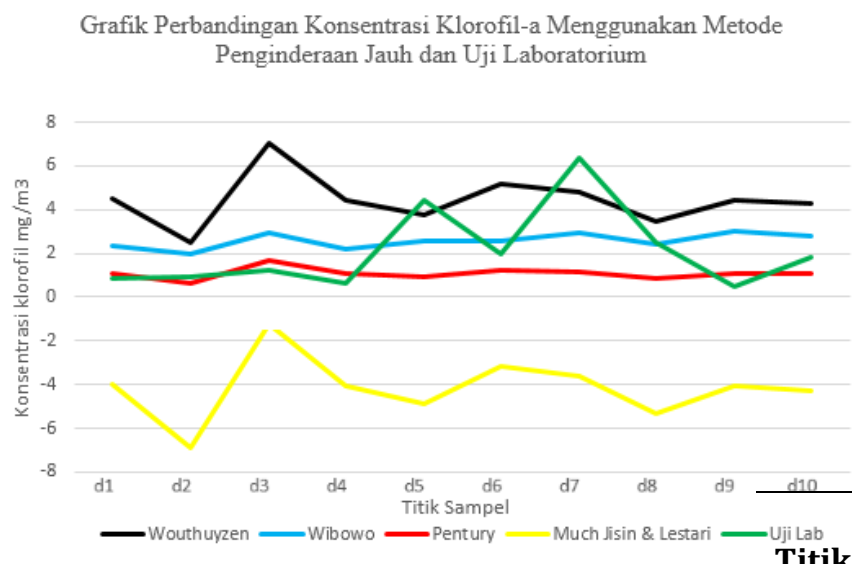

Gambar 3.5 Perbandingan Konsentrasi Klorofil-a Menggunakan Metode Pengindraan Jauh dan Uji P1 Laboratorium di Tambak Tradisional

Nilai minus pada algoritma Much Jisin Arief dan Lestân Laksmi diakibatkan oleh pengaruh reflektansi dasar perairan yang berupa tanah. Pola reflektansi tana meningkat pada dari panjang gelombang biru sampzai panjang gelombang infra merah dekat. Rumus algoritho Much Jisin Arief dan Lestari Laksmi yang menggunakan pengurangan antara band hijau dan band merah in 1910 yang menyebabkan nilai minus karena nilai band merah lebih besar dibandingkan dengan nilai band hijau. Grafik konsentrasi klorofil-a pada sepuluh titik sampel tambak tradisional untuk hasil uji laboratorium dan hasil pengindraan jauh dapat dilihat pada Gambar 3.5.

Perbedaan pola yang signifikan tersebut dikarenakan pada titik D5, D7dan D8 proses pengambilan sampel dilakukan pada air yang terlalu dangkal, berkisar antara $10 \mathrm{~cm}-20 \mathrm{~cm}$. Fitoplankton merupakan organisme yang sangat bergantung pada sinar matahari untuk melakukan proses fotosintesis. Semakin dangkal suatu perairan, maka relatif lebih banyak kandungan sinar mataharinya. Oleh karena itu, hasil uji laboratorium untuk ketiga sampel di atas menghasilkan nilai yang relatif lebih tinggi dan mengakibatkan sampel kurang representatif untuk mewakili nilai konsentrasi klorofil-a pada perairan satu petak tambak. Proses selanjutnya data D5, D7 dan D8 dihilangkan untuk memperbaiki kualitas data lapangan. Grafik setelah dilakukan eliminasi sampel D5, D7 dan D8 dapat dilihat pada Gambar 3.6.

Grafik Perbandingan Konsentrasi Klorofil-a Menggunakan Metode Penginderaan Jauh dan $\mathrm{Uji}_{\mathrm{j}}$ Laboratorium

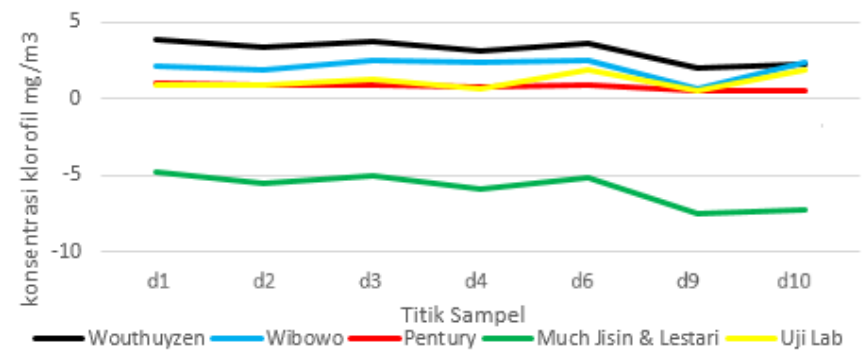

Gambar 3.6 Perbandingan Konsentrasi Klorofil-a

Menggunakan Metode Pengindraan Jauh dan Uji Laboratorium di Tambak Tradisional Hasil Seleksi Data

Hasil perhitungan konsentrasi klorofil-a masing-masing algoritma dan uji laboratorium pada tambak intensif dapat dilihat pada Tabel 3.6.

Tabel 3.6 Konsentrasi Klorofil-a Tambak Tradisional Hasil Metode Pengindraan Jauh dan Uji Lab Hasil Pengolahan Data Pengindraan Jauh

\begin{tabular}{ccccc}
$\begin{array}{c}\text { Wouthuyzen } \\
\text { (mg/m3) }\end{array}$ & $\begin{array}{c}\text { Wibowo } \\
\text { (mg/m3) }\end{array}$ & $\begin{array}{c}\text { Pentury } \\
\text { (mg/m3) }\end{array}$ & $\begin{array}{c}\text { Much Jisin } \\
\text { \& Lestari } \\
\text { (mg/m3) }\end{array}$ & $\begin{array}{c}\text { Uji Lab } \\
\mathbf{m g} / \mathbf{m}^{3}\end{array}$ \\
\hline 8,21398 & 2,460451 & 1,968081 & -0154581 & 4,748507 \\
8,592003 & 2,45956 & 2,055181 & 0,160035 & 0,565587 \\
8,103733 & 2,468303 & 1,94268 & $-0,248487$ & 0,385093 \\
8,668831 & 2,58686 & 2,072883 & 0,222617 & 0,849613 \\
8,654375 & 2,536964 & 2,069552 & 0,210876 & 0,367133 \\
8,55971 & 2,444409 & 2,04774 & 0,133595 & 1,124947 \\
9,111343 & 2,497897 & 2,174841 & 0,574493 & 3,170627 \\
8,738272 & 2,545391 & 2,088883 & 0,278795 & 2,696133 \\
8,923655 & 2,504247 & 2,131596 & 0,427006 & 2,478533 \\
8,739962 & 2,400943 & 2,089272 & 0,280156 & 2,182333 \\
\hline
\end{tabular}

Hasil konsentrasi klorofil-a pada tambak intensif menghasilkan nilai yang relatif lebih tinggi dibandingkan dengan tambak tradisional. Konsentrasi klorofil-a hasil uji laboratorium di tambak intensif menghasilkan nilai $0,367133 \mathrm{mg} / \mathrm{m} 3$ hingga 4,748507 $\mathrm{mg} / \mathrm{m} 3$ sedangkan hasil konsentrasi algoritma Wouthuyzen menghasilkan 
nilai $8,103733 \mathrm{mg} / \mathrm{m} 3$ hingga 9,111343 mg/m3, algoritma Wibowo menghasilkan nilai $2,400943 \mathrm{mg} / \mathrm{m} 3$ hingga 2,58686 mg/m3, algoritma Pentury menghasilkan nilai $1,94268 \mathrm{mg} / \mathrm{m} 3$ hingga 2,174841 mg/m3, algoritma Much Jisin Arief dan Lestari Laksmi menghasilkan nilai $0,248487 \mathrm{mg} / \mathrm{m} 3$ hingga $0,574493 \mathrm{mg} / \mathrm{m} 3$. Grafik konsentrasi klorofil-a pada sepuluh titik sampel tambak intensif untuk hasil uji laboratorium dan hasil pengindraan jauh dapat dilihat pada Gambar 3.7.

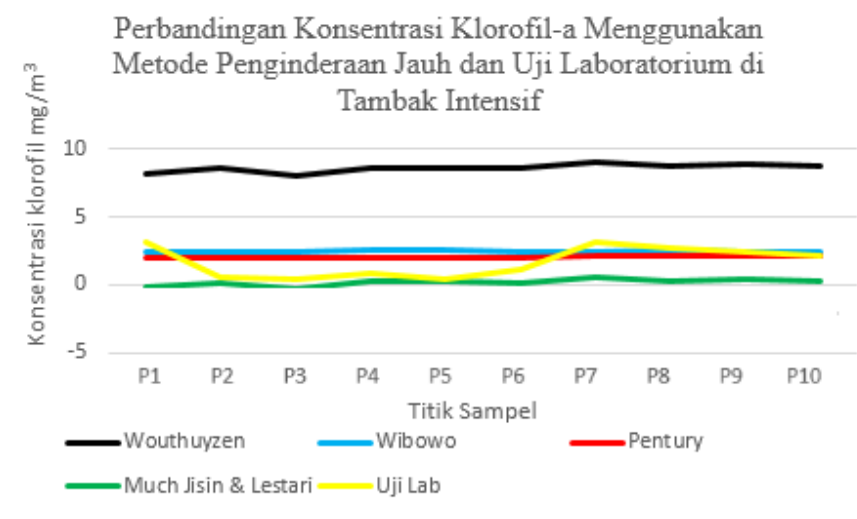

Gambar 3.7. Perbandingan Konsentrasi Klorofil-a Menggunakan Metode Pengindraan Jauh dan Uji Laboratorium di Tambak Intensif

Kasus perbedaan pola pada sampel P1 sama seperti pada kasus tambak tradisional, yakni proses pengambilan sampel yang dilakukan pada perairan yang relatif lebih dangkal yaitu kisaran $10 \mathrm{~cm}-20 \mathrm{~cm}$ yang mengakibatkan berkumpulnya fitoplankton pada perairan dan mengakibatkan nilai konsentrasi klorofil-a hasil uji laboratorium relatif lebih tinggi, dan untuk pengolahan selanjutnya data P1 dihilangkan untuk memperbaiki kualitas data lapangan. Grafik setelah dilakukan eliminasi pada sampel P1 dapat dilihat pada Gambar 3.8.

\section{Perbandingan Konsentrasi Klorofil-a Menggunakan Metode Pengindraan Jauh dan Uji Laboratorium di Tambak Intensif}

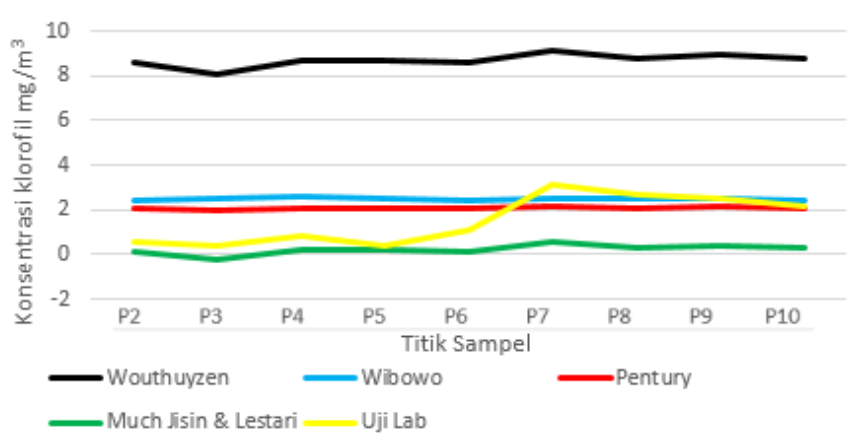

Gambar 3.8. Perbandingan Konsentrasi Klorofil-a

Menggunakan Metode Pengindraan Jauh dan Uji

Laboratorium di Tambak Intensif Hasil Seleksi Data

\subsection{Hasil Uji T Berpasangan}

Hasil uji t berpasangan pada tambak tradisional dapat dilihat pada Tabel 3.7.
Tabel 3.7 Hasil Uji T Berpasangan Pada Tambak Tradisional

\begin{tabular}{ccccc}
\hline & \multicolumn{4}{c}{ Nilai } \\
\cline { 2 - 5 } Parameter & $\begin{array}{c}\text { Wouthuy } \\
\text { zen }\end{array}$ & Wibowo & Pentury & $\begin{array}{c}\text { Much Jisin } \\
\text { dan } \\
\text { Lestari }\end{array}$ \\
\hline Rata-Rata & 2,001 & 0,957 & $-0,332$ & $-7,016$ \\
Standar & 1,238 & 1,238 & 1,238 & 1,608 \\
Deviasi & & 2,297 & $-1,219$ & $-11,544$ \\
T Hitung & 4,276 & 0,061 & 0,269 & 0,000 \\
Signifikasi & 0,005 & & & \\
\hline
\end{tabular}

Uji $t$ sampel berpasangan dalam penelitian ini menggunakan derajat kepercayaan sebesar 95\%. Berdasarkan Tabel 5 dapat diketahui nilai signifikansi masing-masing agoritma pada tambak tradisional. Algoritma Wouthuyzen memiliki nilai signifikansi sebesar 0,05 algoritma Wibowo dkk memiliki nilai signifikansi sebesar 0,061 algoritma Pentury memiliki nilai signifikansi sebesar 0,269 sedangkan algoritma Much Jisin Arief dan Lestari Laksmi memiliki nilai signifikansi sebesar 0. Syarat suatu nilai dikatakan tidak memiliki perbedaan yang signifikan adalah nilai signifikansi hasil uji $\mathrm{t}$ berpasangan $\geqslant 0,05$. Berdasarkan nilai signifikansi tersebut, algoritma Pentury memiliki nilai lebih besar dari 0,05 oleh sebab itu dapat disimpulkan bahwa konsentrasi klorofil-a hasil algoritma Pentury pada tambak tradisional tidak memiliki perbedaan yang signifikan dibandingkan dengan konsentrasi klorofil-a hasil uji laboratorium, sedangkan algoritma yang lain memiliki perbedaan yang signifikan dibandingkan dengan hasil uji laboratorium. Hasil uji t berpasangan pada tambak intensif dapat dilihat pada Tabel 3.8.

Tabel 3.8 Hasil Uji T Berpasangan Pada Tambak Intensif

\begin{tabular}{ccccc}
\hline & \multicolumn{4}{c}{ Nilai } \\
\cline { 2 - 5 } Parameter & Wouthuyzen & Wibowo & Pentury & $\begin{array}{c}\text { Much } \\
\text { Jisin } \\
\text { dan } \\
\text { Lestari }\end{array}$ \\
\hline Rata-Rata & 7,141 & 0,958 & 0,539 & $-1,039$ \\
Standar & 0,898 & 1,098 & 1,047 & 0,932 \\
Deviasi & 23,859 & 2,617 & 1,545 & $-4,211$ \\
T Hitung & 0 & 0,031 & 0,161 & 0,003 \\
Signifikasi & 0 & & & \\
\hline
\end{tabular}

Berdasarkan Tabel 3.8 dapat diketahui nilai signifikansi masing-masing agoritma pada tambak intensif. Algoritma Wouthuyzen memiliki nilai signifikansi sebesar 0,000 algoritma Wibowo dkk memiliki nilai signifikansi sebesar 0,031 algoritma Pentury memiliki nilai signifikansi sebesar 0,161 sedangkan algoritma Much Jisin Arief dan Lestari Laksmi memiliki nilai signifikansi sebesar 0,003. Sama seperti pada uji $t$ pada tambak tradisional, hanya algoritma Pentury yang memiliki nilai lebih besar dari 0,05 oleh sebab itu dapat disimpulkan bahwa konsentrasi klorofil-a hasil algoritma Pentury pada tambak intensif tidak memiliki perbedaan yang signifikan dibandingkan dengan konsentrasi klorofil-a hasil uji laboratorium, 
sedangkan algoritma yang lain memiliki perbedaan yang signifikan dibandingkan dengan hasil uji laboratorium.

\section{Kesimpulan}

Kesimpulan berupa perhitungan konsentrasi klorofil-a menggunakan metode pengindraan jauh bisa dilakukan menggunakan algoritma Wouthuyzen, Wibowo, Pentury, dan algoritma Much Jisin Arief dengan Lestari Laksmi. Hasil perhitungan konsentrasi klorofil-a menggunakan algoritma Wibowo dan algoritma Pentury tidak berbeda jauh dengan konsentrasi klorofil-a hasil uji laboratorium. Hasil perhitungan konsentrasi klorofil-a menggunakan algoritma Wouthuyzen bernilai jauh lebih tinggi dibandingkan dengan konsentrasi klorofil-a hasil uji laboratorium. Hasil konsentrasi klorofil-a menggunakan algoritma Much Jisin Arief dan Lestari Laksmi bernilai minus, jauh lebih rendah dibandingkan dengan konsentrasi klorofil-a hasil uji laboratorium. Konsentrasi klorofil-a terendah pada tambak tradisional yaitu 0,47068 $\mathrm{mg} / \mathrm{m} 3$, konsentrasi tertinggi $1,95017 \mathrm{mg} / \mathrm{m} 3$ dan konsentrasi rata-rata $1,12893 \mathrm{mg} / \mathrm{m} 3$, sedangkan pada tambak intensif konsentrasi terendah 0,36713 mg/m3, konsentrasi tertinggi 3,17063 mg/m3 dan konsentrasi rata-rata $1,53556 \mathrm{mg} / \mathrm{m} 3$. Hasil penelitian ini dapat disimpulkan bahwa konsentrasi klorofil-a hasil algoritma Pentury pada tambak intensif tidak memiliki perbedaan yang signifikan dibandingkan dengan konsentrasi klorofila hasil uji laboratorium, sedangkan algoritma yang lain memiliki perbedaan yang signifikan dibandingkan dengan hasil uji laboratorium.

\section{Pernyataan Konflik Kepentingan}

Penulis menyatakan tidak ada konflik kepentingan dalam artikel ini (The authors declare no competing interest).

\section{Referensi}

Arhatin, R. E. (2010). Modul Pelatihan Pembangunan Indek Kerentanan Pantai.

Arief, M. J. Dan Lestari Laksmi. (2006). Analisis Kesesuaian Perairan Tambak Di Kabupaten Demak Ditinjau Dari Nilai Klorofil-a, Suhu Permukaan Perairan, Dan Muatan Padatan Tersuspensi Menggunakan Data Citra Satelit Landsat 7 ETM+. Jurnal Penginderaan Jauh dan Pengolahan Data Citra Digital Vol 3 No 1 108-118.

Juniarta A., Hartoko A., dan Suryanti. (2016). Analisis Produktivitas Primer Tambak Ikan Bandeng (Chanos Chanos, Forsskal) Dengan Data Citra Satelit Ikonos Di Kabupaten Pati, Jawa Tengah. Jurnal Management of Aquatic Resources (MAQUARES). Volume 5, Nomor 1, 83-90.

Putri, L. K. R. (2014). Deliniasi Citra Dengan Software ArcGis [Skripsi]. Semarang (ID): Universitas Diponegoro.

Sidabutar, D. N. R. (2009). Pendugaan Konsentrasi Klorofila dan Transparansi Perairan Teluk Jakarta dengan Citra Satelit Landsat. Bogor: Program Studi Ilmu dan Teknologi Kelautan Institut Pertanian Bogor.
Triyanto, M. Mukhlis Kamal, dan Niken TM. Pratiwi. (2014). Pemanfaatan Makanan Dan Pertumbuhan Ikan Bandeng (Chanos Chanos) Yang Diintroduksi Di Waduk Ir.H. Djuanda, Jawa Barat. LIMNOTEK Perairan Darat Tropis di Indonesia21 (1) : 64 - 73.

USGS. (2016). LANDSAT 8 (L8) Data Users Handbook. Sioux Falls: Department of the Interior U.S. Geological Survey. 